\title{
Psychological Studies
}

\section{The association between resilience and performance: The mediating role of workers' well-being \\ --Manuscript Draft--}

\begin{tabular}{|c|c|}
\hline Manuscript Number: & PSYI-D-19-00311R1 \\
\hline Full Title: & $\begin{array}{l}\text { The association between resilience and performance: The mediating role of workers' } \\
\text { well-being }\end{array}$ \\
\hline Article Type: & Research in Progress \\
\hline Corresponding Author: & $\begin{array}{l}\text { Silvia Pereira Lopes, Ph.D. } \\
\text { Universidade Europeia } \\
\text { Lisbon, Lisboa PORTUGAL }\end{array}$ \\
\hline \multicolumn{2}{|l|}{$\begin{array}{l}\text { Corresponding Author Secondary } \\
\text { Information: }\end{array}$} \\
\hline Corresponding Author's Institution: & Universidade Europeia \\
\hline \multicolumn{2}{|l|}{$\begin{array}{l}\text { Corresponding Author's Secondary } \\
\text { Institution: }\end{array}$} \\
\hline Corresponding Author E-Mail: & silvia.pereira.lopes@gmail.com;silvia.pereira.lopes@universidadeeuropeia.pt \\
\hline First Author: & Francisca Cantante-Rodrigues, Master \\
\hline \multicolumn{2}{|l|}{ First Author Secondary Information: } \\
\hline \multirow[t]{5}{*}{ Order of Authors: } & Francisca Cantante-Rodrigues, Master \\
\hline & Silvia Lopes, Ph.D. \\
\hline & Ana Sabino, Ph.D \\
\hline & Luís Pimentel, Ph.D. \\
\hline & Paulo César Dias, PhD \\
\hline \multicolumn{2}{|c|}{ Order of Authors Secondary Information: } \\
\hline \multicolumn{2}{|l|}{ Funding Information: } \\
\hline Abstract: & $\begin{array}{l}\text { Associations among resilience, employee well-being (i.e., work engagement and } \\
\text { burnout), and performance were examined. Up to date, to the best of our knowledge, } \\
\text { no studies were carried out exploring the relationship between all three constructs into } \\
\text { the same model from an organizational perspective. Consequently, the principal aim of } \\
\text { this study was to understand and provide evidence regarding the above-mentioned } \\
\text { relationships. Data were collected from a sample of } 249 \text { working professionals. The } \\
\text { findings showed a positive relationship between resilience and work engagement, and } \\
\text { a negative relationship between resilience and burnout. However, while work } \\
\text { engagement was found as being positively and significantly related to performance, the } \\
\text { relationship between burnout and performance was not significant. Additionally, work } \\
\text { engagement seems to partially mediate the relationship between resilience and } \\
\text { performance, since a significant direct relationship between resilience and } \\
\text { performance was also observed. The practical and theoretical implications of these } \\
\text { findings will be discussed. }\end{array}$ \\
\hline
\end{tabular}


Dear Professor Dr. Purnima Singh,

Firstly, we would like to thank you and the reviewer for taking the time and effort necessary to provide such insightful guidance, which has contributed to improving this new version of the paper. We carefully considered the comments provided by the Reviewer. Herein, we explain how we revised the manuscript based on those comments and recommendations.

\section{Reviewer \#1:}

«The study is interesting but needs several improvements:

1- The sample size of the study is only 119 and the number of items is 38. A ratio of 5 respondents per item is recommended as a rule of thumb and this would require 140 respondents. Thus, the authors can increase the sample size or use PLS-based statistical techniques that have proved effective with smaller samples.»

Authors' answer: We understand the reviewer's concerns, and to strengthen the study more data was collected, resulting in a total sample of 249 valid answers. As such, all the statistical analyses were redone. The results obtained were in line with those previously obtained with a smaller sample.

«2- Work engagement is a multi-dimensional construct. Although a single-dimensional construct of work engagement has been found adequate in certain situations, it is unreasonable to use a one-dimensional measure of work engagement without first establishing that it has better psychometric fit than the hypothesized three-dimensional construct. The same comment applies to burnout.»

Authors' answer: The reviewer points out a very important issue. In line with the reviewer recommendation, we performed new confirmatory factor analyses, as follows:

Page 16: «First, we tested a three latent factor model (i.e., vigor, dedication, and absorption, each one as a latent factor) through CFA and then we compared this structure with an alternative model, where all the items loaded onto only one latent factor, namely: work engagement. The three latent factors model showed an acceptable fit to the data $[\chi 2(24)=$ 
79.76, $\mathrm{p}<.01, \mathrm{SRMR}=.04, \mathrm{CFI}=.96, \mathrm{IFI}=.96]$. Concerning the factor loadings, the standardized coefficient estimates were between .28 to .88 . The alternative tested model also showed an acceptable fit to the data $[\chi 2(27)=124.67, \mathrm{p}<.01, \mathrm{SRMR}=.06, \mathrm{CFI}=.92$, $\mathrm{IFI}=.92]$, and differed significantly from the three latent factor model $[\Delta \chi 2(3)=45.51, \mathrm{p}$ $<.01]$. This result seems to suggest that although vigor, dedication, and absorption are included in the same broader construct of work engagement, these three dimensions may represent a specific component within this broader construct.»

Page 17: «First, we tested a two latent factor model (i.e., physical fatigue and cognitive weariness, each one as a latent factor) through CFA and then we compared this structure with an alternative model, where all the items loaded onto only one latent factor, namely, burnout. The two latent factor model showed an acceptable fit to the data $\left[\chi^{2}(26)=41.98\right.$, $\mathrm{p}<.01, \mathrm{SRMR}=.03, \mathrm{CFI}=.99, \mathrm{IFI}=.99]$. Concerning the factor loadings, the standardized coefficient estimates were between .37 to .96 . The alternative tested model also showed an acceptable fit to the data $\left[\chi^{2}(27)=157.56, \mathrm{p}<.01, \mathrm{SRMR}=.06, \mathrm{CFI}=\right.$ .91$, IFI $=.91]$, and differed significantly from the two latent factor model $[\Delta \chi 2(1)=$ $115.58, \mathrm{p}<.01]$. This result seems to suggest that although physical fatigue and cognitive weariness are included in the same broader construct of burnout, these two dimensions may represent a specific component within this broader construct.»

«3- Operationalizing well-being as a combination of work engagement and burnout needs more support from literature»

Authors' answer: We totally agree and in line with this comment, we reformulate the sections entitled "The Concept and Importance of Employee Well-being" and "Engagement and Burnout: Two Constructs for Understanding Well-being at Work" (see, please, from page 4 to page 7 ). 
«4 - On p. 10 lines 33-43, the author(s) mention how work engagement leads to improvement in performance. There is no references for the claims. This needs to be provided.»

Authors' answer: In line with the reviewer' comment we added the following:

Page 11: «Additionally, as noted by Bakker (2009), there are four reasons why engaged employees perform better than non-engaged employees, namely: (1) they experience positive emotions more often, including happiness, joy, and enthusiasm (2) they possess better psychological and physical health, (3) they create their job and personal resources; and (4) they transfer their engagement to others.»

«5- The language of the draft needs improvement and the uniqueness of the study needs to be brought out more clearly.»

Authors' answer: The language of the draft was improved and to highlight the uniqueness of the study we added the following:

Page 2-3: «The study of the above-mentioned relationships has several contributions to the literature and Human Resource management. First, previous studies on the Occupational Health Psychology mainly focus on which job characteristics (e.g., job autonomy, job demands, supervisor support) might affect individuals' well-being at work (MachínRincón, Cifre, Domínguez-Castillo, \& Segovia-Pérez, 2020). As such, the present study innovates by focusing on a crucial personal resource - i.e., resilience - and their contribution to boost desirable outcomes - i.e., work engagement and performance - and buffer an undesirable outcome - i.e. burnout. Second, to the best of our knowledge, this is the first study including into the same model the analysis of resilience, work well-being (i.e., work engagement and burnout), and performance. Thus, the present study adds to the literature by testing a more complex model that includes the analysis of both a determinant (i.e., resilience) and an outcome (i.e., performance) of workers' well-being. Third, we propose with the current study that work well-being is a critical factor that contributes to explain the relationship between individuals' resilience and their performance at work. In other words, with the current study, we aim to shed a light on the mediating role of work well-being in the relationship between resilience and performance. Finally, based on the 
results obtained, it will be possible to indicate a set of Human Resource management policies that could be implemented by managers.».

In closing, we would like to thank the Editor for the opportunity to reformulate our manuscript and the Reviewer again for their comments. We hope that we have dealt with the Reviewer's suggestions satisfactorily.

Yours sincerely,

On behalf of my co-authors, 
Running Head: Resilience and performance

The association between resilience and performance: The mediating role of workers' well-being

\author{
Francisca Cantante-Rodrigues \\ Universidade Europeia, Lisbon, Portugal \\ Sílvia Lopes \\ Universidade Europeia, Lisbon, Portugal \\ CICPSI, Faculdade de Psicologia, Universidade de Lisboa, Portugal
}

Ana Sabino

Universidade Europeia, Lisbon, Portugal

Luís Pimentel

Universidade Europeia, Lisbon, Portugal

Paulo C. Dias

Universidade Católica Portuguesa, Faculty of Philosophy and Social Sciences, Centre for Philosophical and Humanistic Studies, Portugal

Correspondence concerning this article should be addressed to Sílvia Pereira Lopes, Universidade Europeia, Campus da Quinta do Bom Nome, Estrada da Correia, nº53, 1500-210 Lisboa, Portugal (E-mail address:

silvia.pereira.lopes@ universidadeeuropeia.pt; silvia.pereira.lopes@gmail.com). 


\section{Declarations}

- Funding: Not applicable.

- Conflicts of interest/Competing interests: The authors declare that they have no conflict of interest.

- Ethics approval: The study was approved by Universidade Europeia research board. No medical experiments were conducted and no sensitive data was collected.

- Consent to participate: Before start participating in the study, a statement of the study goals and an anonymity and confidentiality warranty were set out at the beginning of the questionnaire, along with the professional identification and contact of the main researcher. Respondents were asked to read these statements before proceeding to answer the questionnaire. They were also informed that their participation was voluntary and they could also freely participate in or give up the study anonymously, at any moment, without any consequence.

- Consent for publication: Not applicable.

- Availability of data and material: Data and a copy of the questionnaire are available upon request to the corresponding author (Dr. Sílvia Lopes silvia.pereira.lopes@gmail.com).

- Code availability: Not applicable.

- Authors' contributions: All authors contributed to the study conception and design. Material preparation, data collection, and analysis were performed by Francisca Cantante-Rodrigues, Sílvia Lopes, and Paulo C. Dias. Ana Sabino and Luís Pimentel helped with the literature review. The first draft of the manuscript was written by Francisca Cantante-Rodrigues and all authors commented on previous versions of the manuscript. All authors read and approved the final manuscript. 


\title{
The association between resilience and performance: The mediating role of workers' well-being
}

\begin{abstract}
Associations among resilience, employee well-being (i.e., work engagement and burnout), and performance were examined. Up to date, to the best of our knowledge, no studies were carried out exploring the relationship between all three constructs into the same model from an organizational perspective. Consequently, the principal aim of this study was to understand and provide evidence regarding the above-mentioned relationships. Data were collected from a sample of 249 working professionals. The findings showed a positive relationship between resilience and work engagement, and a negative relationship between resilience and burnout. However, while work engagement was found as being positively and significantly related to performance, the relationship between burnout and performance was not significant. Additionally, work engagement seems to partially mediate the relationship between resilience and performance, since a significant direct relationship between resilience and performance was also observed. The practical and theoretical implications of these findings will be discussed.
\end{abstract}

Keywords: resilience, employee well-being, work engagement, burnout, performance. 


\section{Introduction}

The Portuguese Association of Health Psychology estimated that, in 2018, approximately $18 \%$ of the working population in Portugal experienced burnout. On the other hand, Aon conducted a study (Aon EMEA Health Survey, 2018) claiming that although Portuguese companies understand the implications of mental health on work wellbeing and performance there is still a lot to grow when it comes to implementation of policies directed to this issue and organizations are not implementing more Human Resources practices regarding this subject mostly due to budget constraints.

The practical implications of mental health in the workplace are gaining increasing relevance as recent study trends are converging to understand better the mechanisms that lead to more engaged and thriving employees (Salanova, Líbano, Llorens, \& Schaufeli, 2013; Youssef \& Luthans, 2007). As such, understanding that engaged employees is a vital asset to the success of organizations marked the starting point of the study. Later on, we will focus on thriving workers who are willing to recover from failure maintaining a positive attitude towards their job. In sum, we want to understand how resilient workers (Carmeli, Friedman, \& Tishler, 2013) can show higher levels of performance (Williams \& Anderson, 1991) through the mechanisms of work engagement (Schaufeli, Bakker, \& Salanova 2006) and burnout (Shirom \& Melamed, 2006).

Methodologically, this is a quantitative method of research study and, therefore, we extracted quantitative data through a semi-structured questionnaire applied to a sample of 249 working individuals in Portugal.

The study of the above-mentioned relationships has several contributions to the literature and Human Resource management. First, previous studies on the Occupational Health Psychology mainly focus on which job characteristics (e.g., job autonomy, job 
demands, supervisor support) might affect individuals' well-being at work (Machín-

Rincón, Cifre, Domínguez-Castillo, \& Segovia-Pérez, 2020). As such, the present study

innovates by focusing on a crucial personal resource - i.e., resilience - and their

contribution to boost desirable outcomes - i.e., work engagement and performance - and

buffer an undesirable outcome - i.e. burnout. Second, to the best of our knowledge, this is

the first study including into the same model the analysis of resilience, work well-being

(i.e., work engagement and burnout), and performance. Thus, the present study adds to the

literature by testing a more complex model that includes the analysis of both a determinant

(i.e., resilience) and an outcome (i.e., performance) of workers' well-being. Third, we

propose with the current study that work well-being is a critical factor that contributes to

explain the relationship between individuals' resilience and their performance at work. In

other words, with the current study, we aim to shed a light on the mediating role of work

well-being in the relationship between resilience and performance. Finally, based on the

results obtained, it will be possible to indicate a set of Human Resource management

policies that could be implemented by managers.

This study divides into five sections: Literature review, Methodology, Results, Discussion, and lastly Conclusions.

\section{The Concept of Resiliency in the Workplace}

Resilience is defined as "the capacity to rebound or bounce back from adversity, conflict, failure or even positive events, progress and increased responsibility" (Luthans, 2002, pp. 702). This construct is usually reactive and occurs after a positive or negative situation has already been encountered. Luthans and Youssef-Morgan (2017) consider 
resilience more outwardly oriented, as external attributions and social resources are integral to this psychological resource.

Moreover, resilience can be developed through three strategies, namely: assetfocused, risk-focused, and process-focused strategies, which emphasize the building and active formation of assets to mitigate risk factors (Masten, 2001; Masten et al. 2009). As such, resilience can be seen as an opportune variable to study because it can be manipulated, and as such it is possible to observe whether resilience contributes to strength or weaken other variables, such as increased work engagement and decreased employees' burnout (Aziz, Widis, \& Wuensch, 2018).

Studies have included resilience as a positive psychological resource part of the psychological capital construct. Together with hope, optimism, and self-efficacy, they form HERO or the construct of psychological capital (Luthans, 2002; Luthans \& YoussefMorgan, 2017; Luthans et al., 2007; Youssef-Morgan \& Luthans, 2015).

It is also common to approach resilience by itself. Robinson (2010) studied adaptive resilience in the context of the social system applying it to the arts field. The author considers resilience is also applicable to the areas of the economy, social change, and natural environments. Although extensively studied in developmental psychology, resilience research and applications are becoming more prominent in organizational psychology. As an example, is the Comprehensive Soldier and Family Fitness training program, established in 2008 by the United States Army to strengthen resilience among soldiers (Cornum, Seligman, \& Matthews, 2011).

\section{The Concept and Importance of Employee Well-being}


Having healthy employees in the organization is vital for the healthy functioning of the company itself, and this means more than the absence of workers' illness or disease, it means the workers should be well and thriving at the workplace (Ryff \& Singer, 2000). As such, in line with World Health Organization (WHO, 2012), occupational health should include employees' well-being as well.

Concerning the evaluation of work-related well-being, there are several constructs used in the literature to do so. However, burnout and workaholism (as indicators of very low well-being), and job satisfaction, happiness at work, and work engagement (as indicators of high well-being) are the concepts more broadly used to evaluate work-related well-being (Brieger, Clercq, \& Meynhardt, 2020; Fisher, 2014; Hakanen, Peeters, \& Schaufeli, 2017; Salanova, Líbano, Llorens, \& Schaufeli, 2013). Additionally, work-related well-being may affect the way individuals globally evaluate their life, i.e., context-free well-being (Carvalho \& Chambel, 2014).

Work is considered a significant feature of our life, which characterizes by consuming a lot of time, energy, and concern. For that reason, the link between an individual's job, well-being, and quality of life has gained substantial attention (Nie, Chua, Yeung, Ryan, \& Chan, 2015). González-Romá, Schaufeli, Bakker, and Lloret (2006) developed a model composed of burnout and work engagement, indicators of employee well-being. The authors consider employee burnout as a response to chronic occupational stress while work engagement is categorized as a positive work-related state of mind. In the same vein, several studies have already used burnout and work engagement for understanding well-being at work (e.g., Babic, Gillis, \& Hansez, 2020; Carvalho \& Chambel, 2017; Lopes \& Chambel, 2017; Machín-Rincón et al., 2020). 


\section{Engagement and Burnout: Two Constructs for Understanding Well-being at Work}

Literature categorizes work engagement as a positive aspect of employee well-being in the workplace. This fulfilling state of mind is characterized by vigor, dedication, and absorption. Therefore, engaged employees are considered to be highly proactive, committed to the organization, and driven by the passion for their work (Beek et al., 2012). Vigor consists of having high levels of persistence and energy while working, as well as, by showing a willingness to invest effort at work. Dedication encloses being strongly involved in the work and a sense of having a job with significance, in which individuals feel enthusiasm, inspiration, pride, and challenge. Finally, absorption consists of being fully focused and deeply absorbed in work, and as such time passes fast, and the individual loses the sense of time (Beek et al., 2012).

Concerning the term burnout, it started to appear regularly in the 1970s in the United States of America. At the time, it was becoming a prevalent reality of employees at work, and that made it so important and controversial for the research field. In fact, Maslach (2001) originally conceptualized burnout as a condition related to work and as frequently occurring in occupations with client-related tasks (e.g., hospital nurses). However, since then, the concept of burnout has been expanded to include all professions (Norlund et al., 2010).

With regard with the measurement of the construct of burnout, Freudenberger's work (1974) was the basis of three conceptual approaches, namely: the Maslach and her colleagues' approach (Maslach, 1982), the Pines and her colleagues' approach (Pines \& Aronson, 1988) and the Shirom and Melamed approach (Shirom \& Melamed, 2006). Regarding the last approach, it was inspired both by the work of Maslach and her colleagues, as well as, the work of the Pines and her colleagues (Shirom, 2003). 
In line with the conceptualization of Shirom and Melamed (2006), burnout can be defined as "an affective state characterized by one's feelings of being depleted of one's physical, emotional, and cognitive energies" (Shirom, 2003, pp. 250), which includes the notion of physical fatigue and cognitive weariness. Physical fatigue concerns the ones' feeling of tiredness and low levels of energy in carrying out daily work tasks (Schilling, Colledge, Brand, Ludyga, \& Gerber, 2019). Cognitive weariness describes feelings of reduced mental agility at work and the feeling of slower thinking (Schilling et al., 2019).

\section{Resiliency as a Predictor of Employee Well-being}

Even the most hopeful and optimistic employees can experience the negative impact of stressors at the workplace. In these situations, resilience caters to the energy and ability to recover, rebound, and return to a stable point. Researchers have discussed that resilience allows for the use of defeats and obstacles as opportunities for growth beyond the equilibrium (Youssef \& Luthans, 2007).

Resilience allows people, not only to reduce the cynical sequels resulting from stress but also possibly prevent those consequences from occurring in the first hand. Fighting against these adverse effects allows people not just to bounce back but also to stand out and become more resistant when facing challenging conditions (Peterson, 2006). Furthermore, as Siebert (2005) stated, higher levels of resilience prepare individuals to be less vulnerable to burnout.

Previous researchers believe that resilient individuals are more eager to quickly recover from adverse situations, which in the future will help them in sustaining well-being (Ryff \& Singer, 2003). Resilience leads to increased feelings of psychological and 
subjective well-being and is negatively associated with stress (Avey, Wernsing, \& Mhatre, 2011; Burton, Pakenham, \& Brown, 2010; Mehta, Grover, DiDonato, \& Kirkhart 2019).

Bakker and Demerouti (2008) exemplify the positive and significant relationship between resilience and work engagement in their study. These authors have collected and analyzed reviews and literature that confirms this relationship.

To better understand the critical mechanisms of developing and maintaining resilience, literature has focused on the integration of different theoretical perspectives on how antecedents of resilience are developed and the actual mechanisms that lead to the ability to sustain well-being and performance during periods of stress (Rook et al., 2018). As an example, the U.S. Army and Air Force made significant investments in developing resilience (Cornum, Matthews, \& Seligman, 2011), and empirical studies provide preliminary evidence to support the efficacy of these initiatives in building positivity, buffering negativity, and promoting well-being among those serving in stressful and mission-critical roles (Luthans \& Youssef-Morgan, 2017).

Furthermore, McGonigal's (2015) developed the "SuperBetter" game, which is designed to build resilience and instruct on how to overcome life challenges. "By playing for just a few minutes a day, more than half a million players are currently leveraging this game to increase their well-being and build their physical, mental, emotional, social resilience" (Luthans \& Youssef-Morgan 2017, p. 33). These games exist to provide tools that can be transferred to real life, and therefore, to help achieve the desired outcomes. Considering the literature review, the following hypothesis was formulated:

Hypothesis 1: Resilience is significantly related to work well-being.

Hypothesis 1a: Resilience is positively related to work engagement.

Hypothesis 1b: Resilience is negatively related to burnout. 


\section{The Concept of Employee Performance}

Magnifying productivity in organizations is one of the main concerns nowadays.

Productivity is the relationship between input, the work performed, and output.

Furthermore, it is assigned to a type of perspective that contributes to every individual to do his job better than the day before (Honari, Mahmoudi, \& Rahmizadeh, 2018). Hence, the source of energy that constitutes the pillar of any job Performance is the human resource.

Organizational performance is a crucial aspect that can be accomplished through the members of the organization, through various stages of input, process, and other outputs. In other words, the employee's behavior corresponds to the desired company's performance. Further, an influential culture in an organization should be committed to supporting employee performance which, in turn, means sustaining the achievement of goals and increasing the firm's performance (Syafii, Thoyib, Nimran, \& Nimran, 2015).

Employee performance can be investigated through quantitative data analysis or qualitative data. To measure employee performance or employee productivity, scholars have used numerous and distinct measures. Several measures have been linked to healthrelated questionnaires - Health and Labor Questionnaire (HLQ), (HPQ), (HWQ), Work and Health Interview (WHI), Work Limitations Questionnaire (WLQ), Work Productivity and Activity Impairment (WPAI), Lam Employment Absence and Productivity Scale (LEAPS), Endicott Work Productivity Scale (EWPS), Sheehan Disability Scale (SDS) and Stanford Presentism Scale (SPS) - (Despiégel, Danchenko, François, Lensberg, \& Drummond, 2012; Prasad, Wahlqvist, Shikiar, \& Shih, 2004; Gingerich, Seaverson, \& Anderson, 2018) to measure employee performance based on their absence, presentism and health risk assessment. On the other hand, separate measures have been developed solely calculating; for example, net sales per employee (Griffin, 1981). Nevertheless, throughout this research, 
our purpose is to embrace employee performance in the workplace in specific other than assessing the health status of employees.

Accordingly, a perceived employee performance measure has been used for the objective of this study based on the research and criteria developed by Williams and Anderson (1991), moreover considered in extent.

\section{IRB, OCBI, and OCBO as a Performance Measure}

Williams and Anderson (1991) developed a performance measure based on a 21item scale and composed of three dimensions: IRB (In Role Behavior), OCBI (Organizational Citizenship Behavior that targets the Individual), and OCBO (Organizational Citizenship Behavior that targets the Organization).

This scale was developed based on previously developed items as well as new items were added. In sum, the scale measures three types of employee behavior. In-role behavior aims to measure employee performance in concordance with the formal requirements that are part of the job description. On the other hand, both OCBI and OCBO tend to assess the extra effort employees demonstrate regarding acts that focus primarily on benefiting the individual or the organization, respectively, and which are not part of their formal day-today duties.

\section{Well-being as a Predictor of Performance Outcome}

Employee well-being in the workplace has been mostly determined through work engagement (Schaufeli, Bakker, \& Salanova, 2006) and burnout (Maslach et al., 2001). On the other hand, employees' performance in the workplace, according to Williams and Anderson (1991) it is based on three dimensions earlier considered - IRB, OCBO, and OCBI. 
According to Schaufeli and Bakker (2004), there is a positive and significant relationship between engagement and employee performance. Bakker, Demerouti, and Verbeke's (2004) study explained that engaged employees obtained higher ratings concerning the in-role behavior (IRB) and the extra-role performance, which can be associated to OCBO and OCBI, indicating that engaged employees are compliant to put more energy into their work and perform better. A later study of Schaufeli, Taris, and Bakker (2006) also settled that engagement in the workplace is positively related to in-role performance.

Bakker, Schaufeli, Leiter, and Taris (2008) disclose that modern organizations expect their employees to be proactive, ambitious, responsible, and committed to highquality performance. Furthermore, organizations require their employees to feel vigorous, dedicated, and absorbed in their daily tasks - in other words, engaged employees represent the competitive advantage and make an absolute distinction for the company they are committed.

Additionally, as noted by Bakker (2009), there are four reasons why engaged employees perform better than non-engaged employees, namely: (1) they experience positive emotions more often, including happiness, joy, and enthusiasm (2) they possess better psychological and physical health, (3) they create their job and personal resources; and (4) they transfer their engagement to others. A recent study of Reijseger, Peeters, Taris, and Schaufeli (2017) examined the relationship between work engagement and employee performance. The authors concluded that, once again, job engagement is positively and significantly related to in-role behavior and extra-role performance.

Concerning the negative aspect of employee well-being in the workplace, burnout, employees who experience burnout disclosed a mental distance from their job as well as 
appraise their performance in a negative way (Beek et al., 2012). Burnout has been regarded as an enduring and static phenomenon that has unfavorable effects on employee health and behavior, e.g. low performance (Hakanen \& Bakker, 2017).

According to Bakker and Costa (2014), when employees are chronically fatigued and present cynicism, they encounter more difficulties in dealing with their job demands. Consequently, employees who endure burnout may be less able to take advantage and profit from their job resources such as social assistance, feedback, and prospects to growth. Employees may be less open to acquiring information and feedback since they are undergoing burnout while lacking energy and initiative for active training. Moreover, they tend to make errors, whereas they will invest less in their work.

A more contemporary study by Giorgi, Mattei, Notarnicola, Petrucci, and Lancia (2018), conducted with a sample of 315 shift-work nurses, across seven hospitals, in Italy, aimed to analyze the relationship between sleep quality, job burnout, and employee performance. The authors observed a positive and significant relationship between burnout and employee performance deterioration.

Thus, the following hypothesis was formulated:

Hypothesis 2: Work well-being is significantly related to performance.

Hypothesis 2a: Work engagement is positively related to performance.

Hypothesis 2b: Burnout is negatively related to performance.

\section{Resiliency as a Predictor of Employee Performance}

In positive organizational behavior, resilience's definition includes the ability to build strengths and virtues for sustainable high performance and well-being based on experiencing and coping with the adverse experience (Luthans, Youssef, \& Avolio, 2007). 
Resilience, therefore, includes two aspects: the adjustment to adversity and bouncing back and sometimes even thriving through adversity (Rook et al., 2018).

Luthans (2002) defines positive organizational behavior as the study of positively oriented human resource strengths and psychological capacities that can be measured, developed, and effectively managed for improved performance.

Pipe et al. (2012) initiated that resilience training resulted in significantly higher levels of productivity and two other studies that assessed observed performance and goal attainment also showed positive trends, with a substantial effect for both of well-being and performance (Arnetz et al., 2009; Grant et al., 2009).

Based on these assumptions, resilience, viewed as a resource, can be valuable regardless of organizational change, and with suitable HR practices, it can adequately develop and maintain employee resilience. The outcomes of appropriate HR practices should also contribute to positive employee results such as job performance, which in turn improves organizational performance.

Resilience emerges as a significant predictor of organizational citizenship behavior - i.e., extra-role performance. It is a relatively unique positive psychological capacity relevant to the workplace, which can be measured, developed, and effectively managed for getting desired outcomes. In fact, previous studies provided empirical evidence for a positive relationship between resilience and OCB (Paul, Bamel, \& Garg 2016). Thus, the following hypothesis was formulated:

Hypothesis 3: Resilience is significantly and positively related to performance.

\section{The mediating role of Employee Well-Being between Resilience and Performance}


Concerning the mediating role of employee well-being in explaining the relationship between resilience and performance, to the best of our knowledge, there is not any study published that combines the constructs of employee resilience, employee performance, and the mediating role of employee well-being in the workplace. Nevertheless, as discussed previously, both employee resilience and employee well-being are strongly related to employee performance.

Paul, Bamel, and Garg (2016), and McManus et al. (2008) suggest that resilience positively relates to desired employee attitudes, behaviors, and performance such as organizational citizenship behavior (OCB). However, the intermediating mechanism through which resilience is translated into OCB remains unclear.

Therefore, a question arises: Is employee well-being a mediator, and, in that case, does it mediate the relationship between employee resilience and their performance?

Based on the literature, we hypothesize that resilience will have a direct and indirect (via work well-being) effect on employees' performance.

As such, the following hypotheses were formulated:

Hypothesis 4: Work Well-Being will partially mediate the relationship between resilience and performance.

Hypothesis 4a: Work engagement will partially mediate the relationship between resilience and performance.

Hypothesis 4b: Burnout will partially mediate the relationship between resilience and performance.

\section{Method}

\section{Participants and procedure}


A sample of 249 individuals working in Portugal was collected. The sample was composed mainly of women (65\%). The youngest participant was 17 years old and the

oldest 61 years old. The average age of the participants was 35 years old $(S D=9.58)$. The participants' majority possesses a bachelor's degree, or a higher level of education completed (87.6\%). Temporary workers represent $40.6 \%$ of the study sample, being the remaining participants identified as permanent workers (50\%), and identified as having "Other employment contract" (9.3\%). The average tenure in the organization was 6 years $(S D=7.81)$, with the minimum length being 1 month, and the maximum length of 35 years. Lastly, around $31 \%$ of the analyzed sample performed supervisory tasks.

The data was extracted through an online questionnaire and the anonymity of the respondents' answers and the opportunity to receive feedback were assured. There was no incentive (cash or otherwise) for participating in this project.

\section{Measures}

Resilience. We used a 6-item scale designed by Carmeli et al. (2013) (e.g., "When encountering a new and difficult task, we are certain we can do it successfully). The participants answered the questionnaire items using a five-point Likert scale, ranging from 1 (Completely Disagree) to 5 (Completely Agree). To examine the psychometric properties of the measure, we performed a Confirmatory Factor Analysis (CFA). We tested a one latent factor model, where all the items loaded onto only one latent factor, namely: Resilience. The one latent factor model showed an acceptable fit to the data $\left[\chi^{2}(9)=46.13\right.$, $p<.01, \mathrm{SRMR}=.06, \mathrm{CFI}=.91, \mathrm{IFI}=.91]$. Concerning the factor loadings, the standardized coefficient estimates were between .49 to .75 . Cronbach's alpha was .80 . Higher values indicate that workers have higher levels of resilience. 
Work Engagement. Work engagement was measured by the Portuguese version of the shortened version of the Utrecht Work Engagement Scale (Schaufeli, Bakker, \& Salanova, 2006), which was used in a previous study with Portuguese Samples (e.g., Lopes \& Chambel, 2014). Work Engagement includes the dimensions of vigor, dedication, and absorption measured each by three items (item examples include "At my work I feel bursting with energy", "I find the work that I do full of meaning and purpose", and "I am immersed in my work", respectively). The participants answered the questionnaire items using a seven-point Likert scale, ranging from 1 (never) to 7 (always, every day). To examine the psychometric properties of the measure, we performed a Confirmatory Factor Analysis (CFA). First, we tested a three latent factor model (i.e., vigor, dedication, and absorption, each one as a latent factor) through CFA and then we compared this structure with an alternative model, where all the items loaded onto only one latent factor, namely: work engagement. The three latent factors model showed an acceptable fit to the data $\left[\chi^{2}(24)=79.76, \mathrm{p}<.01, \mathrm{SRMR}=.04, \mathrm{CFI}=.96, \mathrm{IFI}=.96\right]$. Concerning the factor loadings, the standardized coefficient estimates were between .28 to .88 . The alternative tested model also showed an acceptable fit to the data $\left[\chi^{2}(27)=124.67, \mathrm{p}<.01\right.$, SRMR $=$ $.06, \mathrm{CFI}=.92, \mathrm{IFI}=.92]$, and differed significantly from the three latent factor model $\left[\Delta \chi^{2}\right.$ $(3)=45.51, p<.01]$. This result seems to suggest that although vigor, dedication, and absorption are included in the same broader construct of work engagement, these three dimensions may represent a specific component within this broader construct. Cronbach's alpha was .88. Higher values indicate that workers have higher levels of work engagement.

Burnout. Burnout was assessed through a 9-item scale adapted from the Shirom-Melamed Burnout Measure developed by Shirom and Melamed (2006) and Armon, Shirom and 
Melamed (2012) and validated to Portugal by Gomes (2012). The scale represents physical fatigue and cognitive weariness (item examples include "I feel tired at work" and "In my job, I have difficulty concentrating", respectively) and it is assessed from 1 (never or almost never) to 7 (always). To examine the psychometric properties of the measure, we performed a CFA. First, we tested a two latent factor model (i.e., physical fatigue and cognitive weariness, each one as a latent factor) through CFA and then we compared this structure with an alternative model, where all the items loaded onto only one latent factor, namely, burnout. The two latent factor model showed an acceptable fit to the data $\left[\chi^{2}(26)=\right.$ 41.98, $\mathrm{p}<.01, \mathrm{SRMR}=.03, \mathrm{CFI}=.99, \mathrm{IFI}=.99 \mathrm{]}$. Concerning the factor loadings, the standardized coefficient estimates were between .37 to .96 . The alternative tested model also showed an acceptable fit to the data $\left[\chi^{2}(27)=157.56, p<.01\right.$, SRMR $=.06$, CFI $=.91$, IFI $=.91]$, and differed significantly from the two latent factor model $\left[\Delta \chi^{2}(1)=115.58, p<\right.$ .01]. This result seems to suggest that although physical fatigue and cognitive weariness are included in the same broader construct of burnout, these two dimensions may represent a specific component within this broader construct. Cronbach's alpha was .90. Higher values indicate that workers have higher levels of Burnout.

Performance. It was assessed by a 14-item scale developed by Williams and Anderson (1991), and was already used with Portuguese samples (e.g., Neves, Paixão, Alarcão, \& Gomes, 2014). The scale is assessed from 1 (completely disagree) to 5 (completely agree). An item example includes: "I adequately complete assigned duties". To examine the psychometric properties of the measure, we performed a Confirmatory Factor Analysis (CFA). We tested a one latent factor model, where all the items loaded onto only one latent factor, namely: Performance. The one latent factor model showed an acceptable fit to the 
data $\left[\chi^{2}(67)=188.79, p<.01, \mathrm{SRMR}=.07, \mathrm{CFI}=.93, \mathrm{IFI}=.93\right]$. Concerning the factor loadings, the standardized coefficient estimates were between .40 to .80 . Cronbach's alpha was .89. Higher values indicate that workers have higher levels of Performance.

Control Variables. We controlled for gender $(0=$ Women; $1=$ Men $)$, age (in years) and supervisor $(0=$ No; $1=$ Yes $)$ because these variables were seen as being significantly related to the studied variables (see Table 1).

\section{Results}

\section{Descriptive Analysis}

The means and standard deviations of the study variables are presented in Table 1. As can be seen by analyzing Table 1 , the mean value obtained for resilience $(M=4.23 ; S D$ $=.47$; considering a 5-point Likert scale) indicating that employees present a high level of resilience. The mean value obtained for work engagement $(M=5.71 ; S D=1.03$; considering a 7-point Likert scale) suggested that employees presented relatively high levels of work engagement, while the mean value obtained for burnout $(M=4.14 ; S D=$ 1.31; considering a 7-point Likert scale) indicated that workers occasionally experience burnout. Lastly, the mean value assessed for Performance $(M=4.45 ; S D=.50$; considering a 5-point Likert scale) represents that employees perceive their performance in the workplace at a high level.

In general, the observed pattern of correlations (see Table 1) indicated that resilience correlates positively and significantly with work engagement $(r=.34, p<.01)$ but negatively and significantly with burnout $(r=-.34, p<.01)$. Moreover, we found a significant relationship between resilience and performance $(r=.42, p<.01)$, as well as 
between engagement and performance $(r=.47, p<.01)$. The correlation between burnout and performance has shown to be negative and significant $(r=-.25, p<.01)$.

Insert Table 1 about here

\section{Hypothesis Testing}

Following the correlation results, it is already possible to have an idea of the probable relation between all constructs. By performing the PROCESS macro in SPSS IBM Statistics, it was possible to complete regression analysis and analyze the existence of mediation effects of well-being, as well. The model used for performing the PROCESS macro was Model 4 (Hayes, 2013) which allows up to 10 mediators operating in parallel. For testing the mediation hypothesis, we used 5000 bootstrap samples with a $95 \%$ biascorrected bootstrap confidence interval for all indirect effects.

Regarding the relationship between resilience and work well-being, as we can see through Figure 1, resilience presents a positive and significant relation with work engagement $(\beta=.31, p<.01)$ and a negative relationship with burnout $(\beta=-.33, p<.01)$. Thus, Hypothesis $1 \mathrm{a}$ and $1 \mathrm{~b}$ were supported by the data.

Concerning the relationship between work well-being and performance, we found work engagement as being positively related to performance $(\beta=.35 ; p>.01)$ while burnout was not significantly related to performance $(\beta=-.04 ;$ n.s. $)$. As such the Hypothesis 2a was supported and Hypothesis $2 \mathrm{~b}$ was not supported.

Furthermore, the direct relationship between resilience and performance was found as being positive and significant $(\beta=.27 ; p>.01)$, which supports Hypothesis 3 .

Finally, concerning the mediating Hypothesis, we started by observing a mediating role of work engagement in explaining the relationship between resilience and 
performance, since the indirect effect was significant (indirect effect $=.11, S E=.03, \mathrm{CI}$ : .05 to .18). However, due to the significant relationship observed between resilience and performance $(\beta=.27 ; p>.01)$ the data seem to suggest that work engagement is a partial mediator of the relationship between resilience and performance which is in line with our predictions (Hypothesis 4a was supported). Regarding Hypothesis $4 \mathrm{~b}$ since the indirect effect was not significant (indirect effect $=.01, S E=.02$, CI: -.03 to .06 ) burnout does not seem to play a mediating role in the relationship between resilience and performance which refutes Hypothesis $4 \mathrm{~b}$.

Figure 1 presents all the significant coefficients among the studied variables.

Insert Figure 1 about here

\section{Discussion}

This study started as a desire to undercover the mediating role of work well-being regarding the relationship between resilience and performance. Workplace well-being was evaluated through the constructs of work engagement and burnout (Schaufeli et al., 2006; Shirom \& Melamed, 2006), and the partial mediating role of employee engagement and employee burnout in the relationship between resilience and performance was tested. However, while work engagement is posited as being a positive dimension of work wellbeing, burnout is posited as being a negative one (Schaufeli \& Bakker, 2004).

Bearing in mind the goals of the presented study, a questionnaire was distributed to Portuguese workers who were chosen randomly to better sample the reality of the country. In other words, no specific activity sectors, employees' functions or other demographic characteristics were selected, although we had a higher percentage of enquires $(87.6 \%)$ with 
a higher level of education completed and so it would be beneficial for future studies to assess a more diverse sample when it comes to scholar degrees.

In line with the literature review conducted by Bakker and Demerouti (2008), we also found a positive and significant relationship between resilience and work engagement. As such, the gathered empirical evidence seems to suggest that higher levels of work engagement could be a result of being more resilient (Schaufeli, Salanova, Gonzalez-Roma, \& Bakker 2002). In fact, as previously noted, being resilient at work is a positive psychological resource (Luthans, 2002), and is likely that this resource generates more resources and contributes to workers fell more vigor, dedication, and absorption at the workplace.

According to the literature, stressed workers can present higher levels of exhaustion and, therefore, higher levels of burnout (Demerouti, Bakker, Vardakou, \& Kantas 2003). These workers are not performing in full potential and tend to present lower levels of general health and well-being. In this study, the relationship between resilience and burnout was significant and negative which confirms that higher levels of resilience make an individual less vulnerable to burnout (Siebert, 2005).

Furthermore, results of this study confirm our hypothesis that there is a positive and significant relationship between work engagement and performance meaning that workers presenting higher levels of vigor, absorption, and dedication will demonstrate higher levels of performance confirming, once again, studies on this subject (e.g., Reijseger et al., 2017). When employees feel well while performing their tasks, showing energy, feeling like they are losing track of the time, and they are involved in what they are doing it is likely they show higher levels of productivity since they are focused on performing their tasks successfully. 
On the other hand, burnout was not significantly related to performance in the present study, which might be explained because individuals only experience exhaustion and, therefore, high levels of chronic stress, at a later stage in time (Chambel et al., 2015). Moreover, there are other facts concerning the job-individual relationship that were not considered in this study, such as motivation or commitment, that could also contribute to better explain the relationship between burnout and performance. It is also interesting to analyze that almost half of our sample (approximately 41\%) is in a temporary work position and, as Lopes and Chambel (2014) previously noted, temporary workers may tend to mask the negative aspects of their job because they believe by doing so they will increase the likelihood of achieving a better job position. Furthermore, the majority of temporary workers desire to have a permanent contract (Lopes \& Chambel, 2014). When masking their feelings of stress and pressure in the workplace these workers might think they increase the likelihood of obtaining a permanent position (Lopes \& Chambel, 2017), which may have contributed to the nonsignificant relationship between burnout and performance observed in the current research. To observe whether this alternative explanation is valid to explain this result, future studies should analyze the relationship between burnout and performance comparing a sample of permanent workers with a sample of temporary workers, who perform their activities in the same workplace.

Regarding the direct relationship between resilience and performance, our results show a positive and significant relationship confirming the study of Paul, Bamel, and Garg (2016) which related resilience with organizational citizenship behavior. Practical approaches to this relationship can be useful for organizations (Pipe et al. 2012) meaning that resilience can be trained to improve organizational performance. The ability to "bounce-back” from obstacles can be developed through Human Resources Practices 
applied to the workplace. Examples are activities that unite workers to solve hypothetical problems or games where employees face some obstacles and have to train decisionmaking techniques. Applying real-life problems in the context of gaming can be beneficial to prepare and train future problems that workers might encounter.

The hypothesis of mediation through burnout was not confirmed since burnout presented a non-significant relationship with performance, and as was mentioned before, this means that burnout does not partially mediate the relationship between resilience and performance because one of the conditions to test the mediation hypothesis was not satisfied. As such, it is important to replicate this study to inspect if this pattern of results is maintained.

Finally, in the current research, work engagement was found as being a partial mediator of the relationship between resilience and performance. Since we only found support for a partial mediation, probably the relationship between resilience and performance is explained due to other intervenient variables, besides work engagement. As such, future studies should continue analyzing the mediating role of work engagement in the relationship between resilience and performance, but adding some other constructs as mediators like affective commitment (Meyer \& Allen, 1997) and Motivation (Deci \& Ryan, 2000). In fact, Meyer (2014) recently proposed a conceptual model linking the constructs of work engagement, motivation, and affective commitment. As such, it will be interesting to test empirically in future studies the above-mentioned relationships.

\section{Conclusions}

In our study, the result of mediating analysis found work engagement as a significant partial mediator between resilience and performance which was aligned with what was hypothesized. 

effect.

\section{Research Limitations}

Although this research has important strengths, certain limitations should be taken into consideration when interpreting the results of this study. First, all the measures were based on self-reports, causing concerns about common method bias. Secondly, the sample dimension on this study $(n=249)$ is a small dimension which does not represent Portuguese workers in all dimensions, other than bigger the sample should also be more diverse to better represent the reality of the Portuguese workforce. Furthermore, future studies should continue analyzing the mediating role of work engagement in the relationship between resilience and performance, while adding some other constructs as mediators like affective commitment and motivation. Lastly, the study was performed during a short period having a cross-sectional design. Some of the constructs, such as burnout, should be evaluated over time and studied to obtain results that better represent the true behavior of workers.

\section{Theoretical and Practical Contributions}

Considering the gap in the literature already mentioned, this study contributed with findings that can lead to further studies that consider the relationship between resilience and performance through work engagement. The results of this study showed that although there is no partial mediation through burnout, the mediating role of engagement was statistically significant and could help to explain the relationship between resilience and performance. 
It is interesting to study the perceptions of workers and the impact on behavior and results in the workplace meaning that if there is further investigation on the way workers "bounce-back" from adversities it will be possible to bring up tools that help to prepare the workforce. Organizations could profit from this investigation. For instance, by creating a solid support system among employees, companies are building positivity and space for workers to discuss their constraints. An environment where workers feel safe and supported can help employees to build higher levels of resilience when facing failure because they do not feel alone and therefore would be more engaged in their daily tasks. Games and roleplay situations can also represent a very helpful tool to mimic real-life situations where employees need to act fast and show an assertive and positive response. By training these situations workers will be better prepared and confident about their response and therefore able to face negative situations envisioning a positive outcome while positively affecting their performance.

In sum, if organizations help to build more resilient employees by implementing human resources practices aligned with this theory, workers will engage in their daily tasks and put more dedication and excitement while performing their job, resulting in a more proactive workforce.

\section{References}

Armon, G., Shirom, A., \& Melamed, S. (2012). The Big Five personality factors as predictors of changes across time in burnout and its facets. Journal of Personality, 80(2), 403-427. https://doi.org/10.1111/j.1467-6494.2011.00731.x

Arnetz, B. B., Nevedal, D. C., Lumley, M. A., Backman, L., \& Lublin, A. (2009). Trauma resilience training for police: Psychophysiological and performance effects. Journal 

9030-y

Avey, J. B., Wernsing, T. S., \& Mhatre, K. H. (2011). A longitudinal analysis of positive psychological constructs and emotions on stress, anxiety, and well-being. Journal of Leadership \& Organizational Studies, 18(2), 216-228. https://doi.org/10.1177/1548051810397368

Aziz, S., Widis, A., \& Wuensch, K. (2018). The association between emotional labor and burnout: The moderating role of psychological capital. Occupational Health Science, 2(4), 365-383. https://doi.org/10.1007/s41542-018-0029-1

Babic, A., Gillis, N., \& Hansez, I. (2020). Work-to-family interface and well-being: The role of workload, emotional load, support and recognition from supervisors. SA Journal of Industrial Psychology, 46(1), 1-13. https://doi.org/10.4102/sajip.v46i0.1628

Bakker, A. B. (2009). Building engagement in the workplace. In C. Cooper \& R. Burke (Eds.), The peak performing organization. London: Routledge.

Bakker, A. B., \& Costa, P. L. (2014). Chronic job burnout and daily functioning: A theoretical analysis. Burnout Research, 1, 112-119. https://doi.org/10.1016/j.burn.2014.04.003

Bakker, A. B., \& Demerouti, E. (2008). Towards a model of work engagement. Career Development International, 13(3), 209-223. https://doi.org/10.1108/13620430810870476

Bakker, A. B., Demerouti, E., \& Verbeke, W. (2004). Using the job demands-resources model to predict burnout and performance. Human Resource Management, 43(1), 83-104 https://doi.org/10.1002/hrm.20004 
Bakker, A. B., Schaufeli, W. B., Leiter, M. P., \& Taris, T. W. (2008). Work engagement: An emerging concept in occupational health psychology. Work \& Stress, 22(3), 187-200. https://doi.org/10.1080/02678370802393649

Beek, I., Hu, Q., Schaufeli, W. B., Taris, T. W., \& Schreurs, B. H. (2012). For fun, love, or money: What drives workaholic, engaged, and burned-out employees at work?. Applied Psychology, 61(1), 30-55. https://doi.org/10.1111/j.14640597.2011.00454.x

Brieger, S. A., De Clercq, D., \& Meynhardt, T. (2020). Doing good, feeling good? Entrepreneurs' social value creation beliefs and work-related well-being. Journal of Business Ethics, published online. https://doi.org/10.1007/s10551-020-04512-6

Burton, N. W., Pakenham, K. I., \& Brown, W. J. (2010). Feasibility and effectiveness of psychosocial resilience training: A pilot study of the READY program. Psychology, Health \& Medicine, 15, 266-277. https://doi.org/10.1080/13548501003758710

Carmeli, A., Friedman, Y., \& Tishler, A. (2013). Cultivating a resilient top management team: The importance of relational connections and strategic decision comprehensiveness. Safety Science, 51(1), 148-159. https://doi.org/10.1016/j.ssci.2012.06.002

Carvalho, V. S., \& Chambel, M. J. (2014). Work-to-family enrichment and employees' well-being: High performance work system and job characteristics. Social Indicators Research, 119(1), 373-387. https://doi.org/10.1007/s11205-013-0475-8

Carvalho, V. S., \& Chambel, M. J. (2017). Work-family conflict and enrichment mediates the relationship between job characteristics and well-being at work with Portuguese Marine Corps. Armed Forces \& Society, 44(2), 301-321. https://doi.org/ 10.1177/0095327X17698121 
Chambel, M. J., Sobral, F., Espada, M., \& Curral, L. (2015). Training, exhaustion, and commitment of temporary agency workers: A test of employability perceptions. European Journal of Work and Organizational Psychology, 24(1), 15-30. https://doi.org/10.1080/1359432X.2013.849246

Cornum, R., Matthews, M. D., \& Seligman, M. E. (2011). Comprehensive soldier fitness: Building resilience in a challenging institutional context. American Psychologist, 66(1), 4-9. https://doi.org/10.1037/a0021420

Deci, E. L., \& Ryan, R. M. (2000). The "what”' and “why” of goal pursuits: Human needs and the self-determination of behavior. Psychological Inquiry, 11(4), 227-268. https://doi.org/10.1207/S15327965PLI1104_01

Demerouti, E., Bakker, A. B., Vardakou, I., \& Kantas, A. (2003). The convergent validity of two burnout instruments: A multitrait-multimethod analysis. European Journal of Psychological Assessment, 18, 296-307. https://doi.org/10.1027//10155759.19 .1 .12

Despiégel, N., Danchenko, N., François, C., Lensberg, B., \& Drummond, M. F. (2012). The use and performance of productivity scales to evaluate presenteeism in mood disorders. Value in Health, 15, 1148-1161. https://doi.org/10.1016/j.jval.2012.08.2206

Fisher, C. D. (2014). Conceptualizing and measuring wellbeing at work. In P. Y. Chen \& C. L. Cooper (Eds.), Wellbeing: A complete reference guide (Vol. 3, pp. 9-33). UK: John Wiley \& Sons. https://doi.org/10.1002/9781118539415.wbwell018

Freudenberger, H. J. (1974). Staff burnout. Journal of Social Issues, 30, 159-164. https://doi.org/10.1111/j.1540-4560.1974.tb00706.x 
Gingerich, S. B., Seaverson, E. L., \& Anderson, D. R. (2018). Association between sleep and productivity loss among 598676 employees from multiple industries. American Journal of Health Promotion, 32(4), 1091-1094. https://doi.org/10.1177/0890117117722517

Giorgi, F., Mattei, A., Notarnicola, I., Petrucci, C., \& Lancia, L. (2018). Can sleep quality and burnout affect the job performance of shift-work nurses? A hospital crosssectional study. Journal of Advanced Nursing, 74(3), 698-708. https://doi.org/10.1111/jan.13484

Gomes, A. R. (2012). Medida de "Burnout" de Shirom-Melamed (MBSM) ["Burnout" measure of Shirom-Melamed (MBSM), Unpublished technical report]. Braga, Portugal: Escola de Psicologia, Universidade do Minho.

González-Romá, V., Schaufeli, W. B., Bakker, A. B., \& Lloret, S. (2006). Burnout and work engagement: Independent factors or opposite poles?. Journal of Vocational Behavior, 68(1), 165-174. https://doi.org/10.1016/j.jvb.2005.01.003

Grant, A. M., Curtayne, L., \& Burton, G. (2009). Executive coaching enhances goal attainment, resilience and workplace well-being: A randomized controlled study. The Journal of Positive Psychology, 4, 396-407. https://doi.org/10.1080/17439760902992456

Griffin, R. W. (1981). Task attributes and long-term employee productivity. Academy of Management Proceedings, 1, 176-180. https://doi.org/10.5465/ambpp.1981.4976751

Hakanen, J. J., \& Bakker, A. B. (2017). Born and bred to burn out: A life-course view and reflections on job burnout. Journal of Occupational Health Psychology, 22(3), 354364. https://doi.org/10.1037/ocp0000053 
Hakanen, J. J., Peeters, M. C. W., \& Schaufeli, W. (2017). Different types of employee well-being across time and their relationships with job crafting. Journal of Occupational Health Psychology, 23(2), 289-301. https://doi.org/10.1037/ocp0000081

Hayes, A. F. (2013). Introduction to mediation, moderation, and conditional process analysis: A regression-based approach. New York, NY: Guilford Press.

Honari, H., Mahmoudi, A., \& Rahimizadeh, M. (2018). The role of job motivation in the productivity of human resource in the ministry of youth affairs and sports. Sports Management International Journal, 14(1), 63-74. https://doi.org/10.4127/ch.2018.0130

Lopes, S., \& Chambel, M. J. (2014). Motives for being temporary agency worker: Validity study of one measure according to the self-determination theory. Social Indicators Research, 116(1), 137-152. https://doi.org/10.1007/s11205-013-0273-3

Lopes, S., \& Chambel, M. J. (2017). Temporary agency workers' motivations and wellbeing at work: A two-wave study. International Journal of Stress Management, 24(4), 321-346. https://doi.org/10.1037/str0000041

Luthans, F. (2002). The need for and meaning of positive organizational behavior. Journal of Organizational Behavior: The International Journal of Industrial, Occupational and Organizational Psychology and Behavior, 23(6), 695-706. https://doi.org/10.1002/job.165

Luthans, F., \& Youssef-Morgan, C. M. (2017). Psychological capital: An evidence-based positive approach. Annual Review of Organizational Psychology and Organizational Behavior, 4, 339-366. https://doi.org/10.1146/annurev-orgpsych032516-113324 
Luthans, F., Avolio, B. J., Avey, J. B., \& Norman, S. M. (2007). Positive psychological capital: Measurement and relationship with performance and satisfaction. Personnel Psychology, 60(3), 541-572. https://doi.org/10.1111/j.1744-6570.2007.00083.x

Luthans, F., Youssef, C. M., \& Avolio, B. J. (2007). Psychological capital: Developing the human competitive edge. Oxford: Oxford University Press.

Luthans, F., \& Youssef-Morgan, C. M. (2017). Psychological capital: An evidence-based positive approach. Annual Review of Organizational Psychology and Organizational Behavior, 4, 339-366. https://doi.org/10.1146/annurev-orgpsych$032516-113324$

Machín-Rincón, L., Cifre, E., Domínguez-Castillo, P., \& Segovia-Pérez, M. (2020). I am a leader, I am a mother, I can do this! The moderated mediation of psychological capital, work-family conflict, and having children on well-being of women leaders. Sustainability, 12(5), 2100. https://doi.org/10.3390/su12052100

Maslach, C. (1982). Burnout: The cost of caring. Englewood Cliffs, NJ: Prentice Hall.

Maslach, C. (2001). What have we learned about burnout and health?. Psychology \& Health, 16(5), 607-611. https://doi.org/10.1080/08870440108405530

Maslach, C., Schaufeli, W. B., \& Leiter, M. P. (2001). Job Burnout. Annual Review of Psychology, 52, 397-422. https://doi.org/10.1146/annurev.psych.52.1.397

Masten, A. S. (2001). Ordinary magic: Resilience processes in development. American Psychologist, 56(3), 227-238. https://doi.org/10.1037/0003-066X.56.3.227

Masten, A. S., Cutuli, J. J., Herbers, J. E., \& Reed, M. G. J. (2009). Resilience in development. In C. R. Snyder \& S. J. Lopez (Eds.), Oxford handbook of positive psychology (pp. 117-131). Oxford: Oxford University Press.

McGonigal, J. (2015). SuperBetter: The power of living gamefully. New York: Penguin. 
McManus, S., Seville, E., Vargo, J., \& Brunsdon, D. (2008). Facilitated process for improving organizational resilience. Natural Hazards Review, 9(2), 81-90. https://doi.org/10.1061/(ASCE)1527-6988(2008)9:2(81)

Mehta, M. H., Grover, R. L., DiDonato, T. E., \& Kirkhart, M. W. (2019). Examining the positive cognitive triad: A link between resilience and well-being. Psychological Reports, 122(3), 776-788. https://doi.org/10.1177/0033294118773722

Meyer, J. P. (2014). Employee commitment, motivation, and engagement: Exploring the links. In M. Gagné (Ed.), The Oxford handbook of work engagement, motivation, and self-determination theory (pp. 33-49). New York, USA: Oxford University Press.

Meyer, J. P., \& Allen, N. J. (1997). Commitment in the workplace: Theory, research, and application. Thousand Oaks, California: Sage.

Neves, P. C., Paixão, R., Alarcão, M., \& Gomes, A. D. (2014). Organizational citizenship behavior in schools: Validation of a questionnaire. The Spanish Journal of Psychology, 17, E17. https://doi.org/10.1017/sjp.2014.20

Nie, Y., Chua, B. L., Yeung, A. S., Ryan, R. M., \& Chan, W. Y. (2015). The importance of autonomy support and the mediating role of work motivation for well-being: Testing self-determination theory in a Chinese work organization. International Journal of Psychology, 50(4), 245-255. https://doi.org/10.1002/ijop.12110

Norlund, S., Reuterwall, C., Höög, J., Lindahl, B., Janlert, U., \& Birgander, L. S. (2010). Burnout, working conditions and gender-results from the northern Sweden MONICA Study. BMC Public Health, 10(1), 326. https://doi.org/10.1186/14712458-10-326 
Paul, H., Bamel, U. K., \& Garg, P. (2016). Employee resilience and OCB: Mediating effects of organizational commitment. Vikalpa, 41(4), 308-324. https://doi.org/10.1177/0256090916672765

Peterson, C. (2006). A primer in positive psychology. New York, NY: Oxford University Press.

Pines, A., \& Aronson, E. (1988). Career burnout: Causes and cures. New York Free Press.

Pipe, T. B., Buchda, V. L., Launder, S., Hudak, B., Hulvey, L., Karns, K. E., \& Pendergast, D. (2012). Building personal and professional resources of resilience and agility in the healthcare workplace. Stress and Health, 28, 11-22. https://doi.org/10.1002/smi.1396

Prasad, M., Wahlqvist, P., Shikiar, R., \& Shih, Y. C. T. (2004). A review of self-report instruments measuring health-related work productivity. Pharmacoeconomics, 22(4), 225-244. https://doi.org/10.2165/00019053-200422040-00002

Reijseger, G., Peeters, M. C. W., Taris, T. W., \& Schaufeli, W. B. (2017). From motivation to activation: Why engaged workers are better performers. Journal of Business and Psychology, 32, 117-130. https://doi.org/10.1007/s10869-016-9435-z

Robinson, M. (2010). Making adaptive resilience real. London: Arts Council England.

Rook, C., Smith, L., Johnstone, J., Rossato, C., Sánchez, G. F. L., Suárez, A. D., \& Roberts, J. (2018). Reconceptualising workplace resilience-A cross-disciplinary perspective. Anales De Psicología/Annals of Psychology, 34(2), 332-339. https://doi.org/10.6018/analesps.34.2.299371

Ryff, C. D., \& Singer, B. (2000). Interpersonal flourishing: A positive health agenda for the new millennium. Personality and Social Psychological Review, 4, 30-44. https://doi.org/10.1207/s15327957pspr0401_4 
Ryff, C. D., \& Singer, B. (2003). Flourishing under fire: Resilience as a prototype of challenged thriving. In C. L. M. Keyes \& J. Haidt (Eds.), Flourishing: Positive psychology and the life well-lived (pp. 15-36). Washington, DC: American Psychological Association.

Salanova, M., Líbano, M. Del, Llorens, S., \& Schaufeli, W. B. (2013). Engaged, workaholic, burned-out or just 9-to-5? Toward a typology of employee well-being. Stress \& Health, 30, 71-82. https://doi.org/10.1002/smi.2499

Schaufeli, W. B., \& Bakker, A. B. (2004). Job demands, job resources, and their relationship with burnout and engagement: A multi-sample study. Journal of Organizational Behavior, 25(3), 293-315. https://doi.org/10.1002/job.248

Schaufeli, W. B., Bakker, A. B., \& Salanova, M. (2006). The measurement of work engagement with a short questionnaire: A cross-national study. Educational and Psychological Measurement, 66(4), 701-716. https://doi.org/10.1177/0013164405282471

Schaufeli, W. B., Salanova, M., Gonzalez-Roma, V., \& Bakker, A. B. (2002). The measurement of engagement and burnout: A confirmative analytic approach. Journal of Happiness Studies, 3, 71-92. https://doi.org/10.1023/A:1015630930326

Schaufeli, W. B., Taris, T. W., \& Bakker, A. B. (2006). Dr. Jekyll and Mr. Hyde: On the differences between work engagement and workaholism. In R.J. Burke (Ed.), Research companion to working time and work addiction (pp. 193-217). Northampton: Edward Elgar.

Schilling, R., Colledge, F., Brand, S., Ludyga, S., \& Gerber, M. (2019). Psychometric properties and convergent validity of the Shirom-Melamed burnout measure in two 
German-speaking samples of adult workers and police officers. Frontiers in Psychiatry, 10, 536. https://doi.org/10.3389/fpsyt.2019.00536

Shirom, A. (2003). Job-related burnout: A review. In J. C. Quick \& L. E. Tetrick (Eds.), Handbook of occupational health psychology (p. 245-264). Washington, DC: American Psychological Association.

Shirom, A., \& Melamed, S. (2006). A comparison of the construct validity of two burnout measures in two groups of professionals. International Journal of Stress Management, 13(2), 176. https://doi.org/ 10.1037/1072-5245.13.2.176

Siebert, A. (2005). The Resiliency Advantage. San Francisco, California: Berrett Koehler Publishers, Inc.

Syafii, L. I., Thoyib, A., Nimran, U., \& Nimran, D. (2015). The role of corporate culture and employee motivation as a mediating variable of leadership style related with the employee performance (Studies in Perum Perhutani). Procedia - Social and Behavioral Sciences, 211, 1142-1147. https://doi.org/10.1016/j.sbspro.2015.11.152

WHO (World Health Organization) (2012). Measurement of and target-setting for wellbeing: An initiative by the WHO Regional Office for Europe. Copenhagen, Denmark: WHO Regional Office for Europe. Retrieved from http://www.euro.who.int/_data/assets/pdf_file/0020/167402/e96764.pdf

Williams, L. J., \& Anderson, S. E. (1991). Job satisfaction and organizational commitment as predictors of organizational citizenship and in-role behaviors. Journal of Management, 17(3), 601-617. https://doi.org/10.1177/014920639101700305

Youssef, C. M., \& Luthans, F. (2007). Positive organizational behavior in the workplace: The impact of hope, optimism, and resilience. Journal of Management, 33(5), 774800. https://doi.org/10.1177/0149206307305562 
Youssef-Morgan, C. M., \& Luthans, F. (2015). Psychological capital and well-being. Stress and Health, 31(3), 180-188. https://doi.org/10.1002/smi.2623 


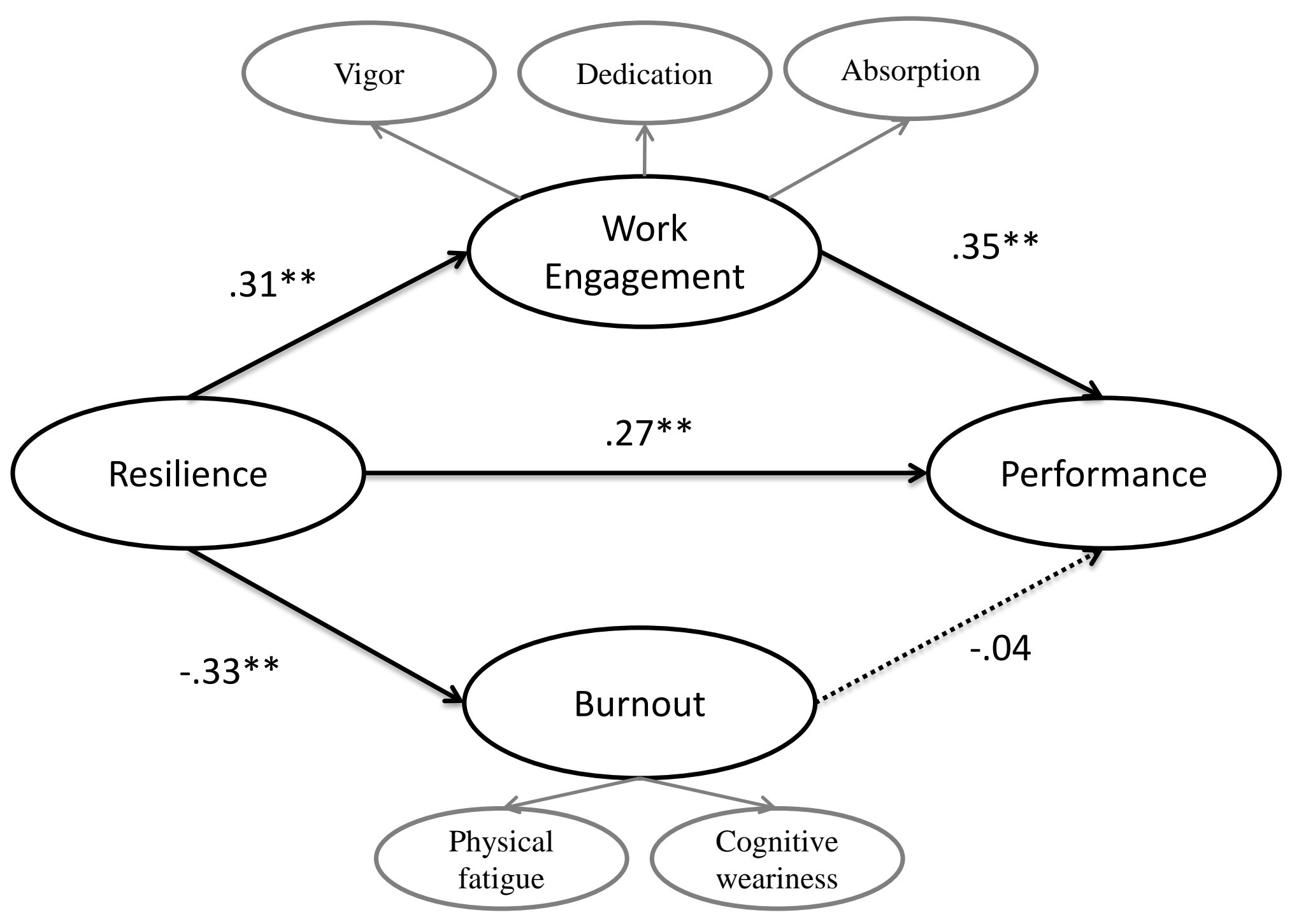

Note: ${ }^{*} p<.01{ }^{*} p<.05 ; ; \longrightarrow$ significant path; $\cdots . . .>$ non-significant path.

Figure 1. Standardized estimates for the partially-mediated model. 
Table 1. Means, standard deviations, and correlation matrix among the studied variables.

\begin{tabular}{|c|c|c|c|c|c|c|c|c|}
\hline & \multicolumn{8}{|c|}{$r$ Sample } \\
\hline & $M$ & $S D$ & 1. & 2. & 3. & 4. & 5. & 6. \\
\hline 1. Gender & $.35^{\mathrm{a}}$ & $.48^{\mathrm{a}}$ & & & & & & \\
\hline 2. Age & 35.26 & 9.58 & $.14^{*}$ & & & & & \\
\hline 3. Supervisor & $.31^{\mathrm{a}}$ & $.46^{\mathrm{a}}$ & $.17^{* *}$ & $.29^{* *}$ & & & & \\
\hline 4. Resilience & 4.23 & .47 & .07 & $.13^{*}$ & $.13^{*}$ & & & \\
\hline 5. Work Engagement & 5.71 & 1.03 & .09 & $.22^{* *}$ & .09 & $.34^{* *}$ & & \\
\hline 6. Burnout & 4.14 & 1.31 & $-.14^{*}$ & $-.14^{*}$ & -.02 & $-.34^{* *}$ & $-.34^{* *}$ & \\
\hline 7. Performance & 4.45 & .50 & .02 & $.16^{*}$ & $.22^{* *}$ & $.42^{* *}$ & $.47^{* *}$ & $-.25^{* *}$ \\
\hline
\end{tabular}

Notes: **: $p<.01 ; *: p<.05 ;{ }^{\text {a. }}$ : without a statistical meaning because Gender $(0=$ Women; $1=$ Men $)$ and Supervisor $(0=$ No; $1=$ Yes $)$ are dummy coded variables. 